\title{
Vascular anatomy and its relationship to pathology in retinoschisis
}

\author{
Adrian $\mathrm{Au}^{1} \cdot$ David Sarraf ${ }^{1,2}$ \\ Received: 16 October 2018 / Accepted: 18 October 2018 / Published online: 12 December 2018 \\ (c) The Royal College of Ophthalmologists 2018
}

In this issue of Eye, Fragiotta et al. present the interesting findings of an optical coherence tomography angiography (OCTA) case study in which they display remarkable vascular flow bridging the schitic cavities in the inner nuclear layer (INL) of a patient with X-linked juvenile retinoschisis (XLJR). This is in contrast to a patient with stellate nonhereditary idiopathic foveomacular retinoschisis (SNIFR) where the schitic cavities, located in Henle's fiber layer (HFL), are larger and fail to display evidence of vascular flow. These OCTA findings provide important insight into the mechanism of schisis formation in these two disorders and greater understanding of the organizational anatomy of the retinal capillary plexus, which has recently been debated in numerous publications [1-3].

Through the use of OCTA, Fragiotta et al. astutely observe cysts in the INL characterized by continuous vascular flow in the tissues that bridge the INL. This may explain the regular and restricted size of the INL cysts as illustrated in the case of XLJR. This is in contrast to cysts located in the central fovea or HFL where the absence of the bridging vascular plexus facilitates expansion of fluid as displayed in the case of SNIFR. Fragiotta et al. provide a convincing explanation and mechanism to explain the observation that cysts in the central fovea and HFL tend to be larger and less uniform than cysts that occur in the INL.

The bridging tissue of macular schisis has been attributed to Müller cells, whose cell bodies are located in the INL and extend in a bi-directional pattern to span nearly the entire retina $[4,5]$. Müller cells provide the primary structural support for the fovea and encapsulate the vessels of the deep

David Sarraf

sarraf@jsei.ucla.edu

1 Retinal Disorders and Ophthalmic Genetics Division, Stein Eye Institute, University of California, Los Angeles, Los Angeles, CA, USA

2 Greater Los Angeles VA Healthcare Center, Los Angeles, CA, USA vascular plexus $[5,6]$. The different location of the schitic cavities may be explained by localized dysfunction in the cell bodies and dendrites of Müller cells in XLJR and SNIFR, respectively. Without the structural support that Müller cells provide, there is insufficient extracellular matrix stability for the retinal cells. As a result, the retinal and Müller cells degenerate and manifest as INL and HFL 'empty' cysts with the bridging tissue representing remnants of the degenerated Müller cells [7].

Disease can provide clues regarding normal anatomy [3]. The OCTA analysis by Fragiotta et al. indicates that there is likely continuous flow between the intermediate and deep retinal capillary plexus located at the inner and outer border of the INL, respectively. And so the presence of blood flow bridging the INL provides evidence of a predominantly serial direction of vascular perfusion in the retinal capillary plexus in which venous outflow is predominantly located at the level of the deep retinal capillary plexus. This has recently been validated by an OCTA study displaying collateralization that always tracks through the deep vascular plexus in eyes with retinal vein occlusion [8]. This has been further supported by the demonstration of an ischemic cascade in which retinal infarction starts at the perivenular pole of the DCP with milder ischemic injury and progresses through the INL and into the inner retina with more severe vascular obstruction $[9,10]$.

While the case studies of Fragiotta et al. illuminate various anatomical concepts, more study is necessary to better understand and clinically differentiate the various cystic lesions that can occur in the retina and the mechanisms of their formation. Cystic lesions in the macula can have diverse etiologies including exudative cystoid macular edema (CME), macular schisis, and microcystic degeneration [6]. Differentiation by OCT or OCTA can be very challenging although the cysts of microcystic degeneration tend to present as narrow, vertically oriented, slit-like spaces which can be very characteristic [11]. The role of the Müller cell may be critical in these pathoanatomical considerations and clinicopathological correlations would be very supportive. A similar pattern of INL cavitation called 
"microcystic macular edema" occurs in a range of optic neuropathies including those associated with multiple sclerosis, neuromyelitis optica, and glaucoma [11]. While the underlying cause of these structural changes may vary with each associated disease, the numerous regularly spaced vessels bridging the INL between the ICP and DCP are likely to influence the anatomic pattern seen with all. Fragiotta et al. should be congratulated for providing greater understanding of these anatomical concepts and for establishing a platform to initiate further investigative efforts [12].

\section{Compliance with ethical standards}

Conflict of interest The authors declare that they have no conflict of interest.

\section{References}

1. Fouquet S, Vacca O, Sennlaub F, Paques M. The 3D retinal capillary circulation in pigs reveals a predominant serial organization. Investig Ophthalmol Vis Sci. 2017;58:5754-63.

2. Nesper PL, Fawzi AA. Human parafoveal capillary vascular anatomy and connectivity revealed by optical coherence tomography angiography. Investig Ophthalmol Vis Sci. 2018;59:3858-67.

3. Garrity ST, Paques M, Gaudric A, Freund KB, Sarraf D. Considerations in the understanding of venous outflow in the retinal capillary plexus. Retina. 2017;37:1809-12.
4. Mooy CM, Van Den Born LI, Baarsma S, Paridaens DA, Kraaijenbrink T, Bergen A, et al. Hereditary X-linked juvenile retinoschisis: a review of the role of Muller cells. Arch Ophthalmol. 2002;120:979-84.

5. Gass JDM. Muller cell cone, an overlooked part of the anatomy of the fovea centralis: Hypotheses concerning its role in the pathogenesis of macular hole and foveomacular retinoschisis. Arch Ophthalmol. 1999;117:821-3.

6. Spaide RF. Retinal vascular cystoid macular edema: review and new theory. Retina. 2016;36:1823-42.

7. Bringmann A, Pannicke T, Grosche J, Francke M, Wiedemann P, Skatchkov SN, et al. Müller cells in the healthy and diseased retina. Prog Retin Eye Res. 2006;25:397-424.

8. Adhi M, Bonini Filho MA, Louzada RN, Kuehlewein L, De Carlo TE, Baumal CR, et al. Retinal capillary network and foveal avascular zone in eyes with vein occlusion and fellow eyes analyzed with optical coherence tomography angiography. Investig Ophthalmol Vis Sci. 2016;57:OCT486-94.

9. Bakhoum MF, Freund KB, Dolz-Marco R, Leong BC, Baumal CR, Duker JS, et al. Paracentral acute middle maculopathy and the ischemic cascade associated with retinal vascular occlusion. Am J Ophthalmol. 2018;195:143-53.

10. Ghasemi Falavarjani K, Phasukkijwatana N, Freund KB, Cunningham ETJ, Kalevar A, McDonald HR, et al. En face optical coherence tomography analysis to assess the spectrum of perivenular ischemia and paracentral acute middle maculopathy in retinal vein occlusion. Am J Ophthalmol. 2017;177:131-8.

11. Chen X, Kuehlewein L, Pineles SL, Tandon AK, Bose SX, Klufas $\mathrm{MA}$, et al. En face optical coherence tomography of macular microcysts due to optic neuropathy from neuromyelitis optica. Retin Cases Brief Rep. 2015;9:302-6.

12. Lumbroso B, Huang D, Romano A, Rispoli M, Coscas G. Clinical En Face OCT Atlas, First. Ltd. New Delhi, India: Jaypee Brothers Medical Publishers; 2013. 